\title{
Nonlinear Static Analysis Procedures for Seismic Performance Evaluation of Existing Buildings - Evolution and Issues
}

\author{
Fawad Ahmed Najam ${ }^{(\bowtie)}$ \\ School of Engineering and Technology (SET), \\ Asian Institute of Technology (AIT), Bangkok, Thailand \\ fawad.ahmed.najam@ait.ac.th, fawad.najam@gmail.com
}

\begin{abstract}
For a quick performance evaluation of existing buildings under an anticipated ground shaking, the nonlinear static analysis procedures (NSPs) are always an attractive option for practicing engineers. Compared to these NSPs, the detailed nonlinear response history analysis (NLRHA) for a sophisticated 3D finite element model requires far more computational and modeling effort. Sometimes the seismic performance evaluation of a large number of buildings is required in order to assess the seismic vulnerability and loss estimation for a particular study area. The applications and relative accuracy of various available NSPs become even more relevant in such scenarios. Over last several decades, the NSPs have passed through a series of proposed modifications and improvements which kept the interest awakened among practicing engineers and academicians. This paper is a review of all such improvements and provides a brief account of various approaches in the NSPs, their inherent assumptions, sources of uncertainties, limitations and associated challenges.
\end{abstract}

Keywords: Nonlinear static procedures - ASCE 41 - NSPs · Seismic performance evaluation $\cdot$ Existing buildings

\section{Introduction}

The advent of latest computing tools, software applications and highly efficient processing units have almost revolutionized the current structural engineering practice in terms of convenient implementation of various (otherwise considered onerous) nonlinear analysis procedures. A wide range of commercially available structural analysis programs makes it possible for practicing engineers to use this computing potential at its maximum. However, the demand for even faster analysis methods and tools for rapid estimation of building response is still increasing due to the increasing requirements. The constantly evolving complex and unsymmetrical 3D geometries, various advanced modeling techniques, the requirement of improved understanding of complex nonlinear phenomena, innovative construction practices and the use of new materials, are some of the recent challenges for structural designers. The detailed nonlinear response history analysis (NLRHA) is considered the most accurate analysis procedure to determine the true nonlinear seismic demands both for the design of new buildings, as well as for the performance evaluation of existing buildings. However, for a 
reasonably sophisticated inelastic structural model, the detailed NLRHA procedure can still take a significant amount of time, computational effort and other resources, and therefore, is still considered a cumbersome and tedious process. One has to step through a detailed process of selecting a site-compatible set of ground motions records, creating a 3D inelastic model, running dynamic analysis in both principal directions and eventually getting results. The process has to be repeated for all selected ground motions, at the end of which, one has to embed in a bulk of numerical data in order to extract useful information for design decision-making. In the practice of common design offices, the implementation of this detailed procedure may not be warranted for all buildings. Practicing structural engineers are always interested in simplified analysis procedures that are although approximate, yet retain well-enough theoretical basis, and can serve as an alternative to the detailed NLRHA procedure. The use of such approximate analysis procedures can also be very handy for a rapid estimation of lateral stiffness required to avoid certain maximum tolerable inter-story drifts. They are also useful in situations where a relatively quicker estimation of seismic demand is required for a large number of building structures in order to assess the seismic vulnerability and loss estimation for a particular study area. The question of how accurately the building response can be captured by a certain approximate analysis becomes even more relevant in such cases.

Over last several decades, various studies have proposed simplifications in terms of approximations in structural models, seismic loading, analysis methods or any combination of these areas. The earlier approaches towards developing approximate methods were based on the use of simplified structural models subjected to simplified loading types. For the purpose of structural design, the seismic load was historically idealized as a simple mass-proportional lateral static loading resisted by the elastic structural model. With the developments in the areas of modal analysis and the response spectrum analysis (RSA), the role of natural periods in controlling the seismic demands was recognized. Soon with the development of dynamic analysis solvers and computer programs in mid-1960s and 1970s, and with the availability of more ground motion records, the use of detailed dynamic analysis procedures based on the direct integration solution of the governing equations of motion was established. In the field of structural modeling, various simplified models that were intended to capture some specific deformational behavior with a reasonable accuracy, were also proposed. These include, for example, the "stick models" which take into account only the shear-type deformations, or the flexure-shear models which accounts for the interaction among the components' behaviors in flexure and shear respectively. An example of such approximate models for building structures is a "shear beam-flexural beam" equivalent continuum model (Miranda 1999). It consists of a combination of a shear beam and a flexural beam connected with rigid links. The ratio of their stiffness is set such that the behavior and response of the continuum model corresponds to that of the actual building. Figure 1 shows a wide spectrum of proposed simplifications in the overall seismic analysis process over last several decades. 


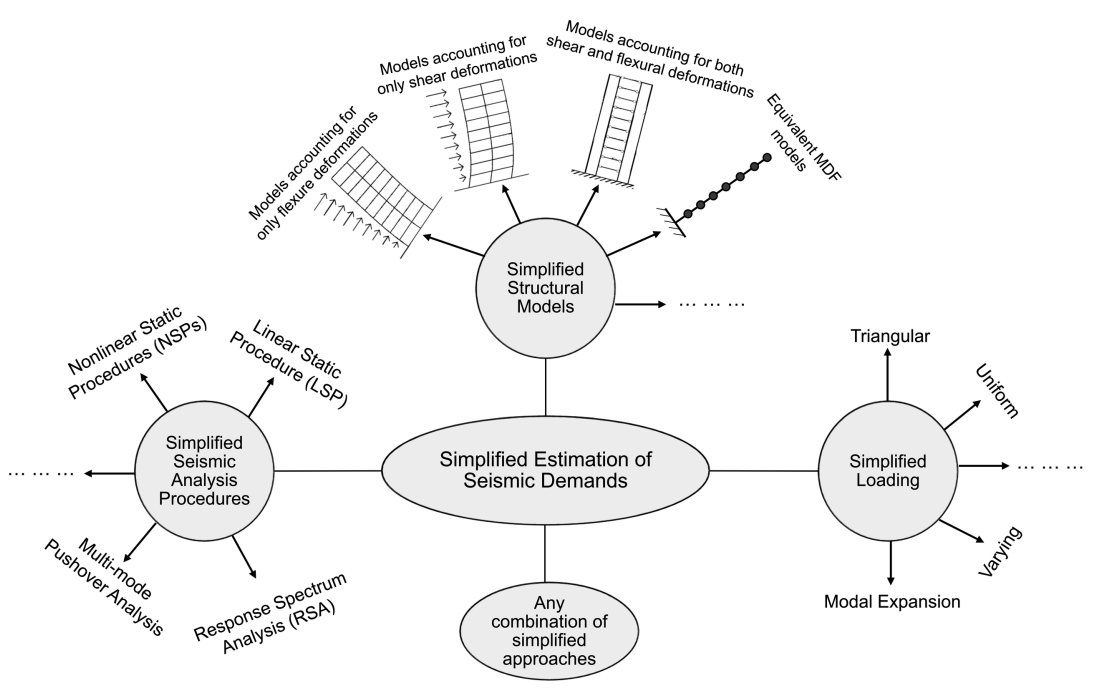

Fig. 1. Some proposed simplifications in the overall seismic analysis process

\section{Nonlinear Static Analysis Procedures (NSPs)}

Although the detailed nonlinear response history analysis (NLRHA) is the most accurate procedure to determine the true nonlinear seismic demand of buildings, for most practical cases (and especially for determining the design demands of new structures), the response spectrum analysis (RSA) procedure is used. The RSA procedure starts with the determination of the linear elastic demands for all significant vibration modes of the structure, which are then combined using an appropriate modal combination rule. Considering the expected ductility of structure and the over-strength, the combined force demands are reduced by a response modification factor (usually denoted by $R$ ) to get the inelastic seismic force demands. For the buildings with seismic response primarily dominated by the fundamental vibration mode (low- to mid-rise buildings), the equivalent lateral force analysis procedure can also be applied. In this procedure, the seismic loading is idealized as an equivalent static force pattern applied to a linear elastic structural model. In various structural design codes and performancebased seismic evaluation guidelines, this equivalent lateral force analysis is referred to as the linear static procedure (LSP).

The nonlinear counterpart of the LSP is referred to as the nonlinear static procedure (NSP) (i.e. a nonlinear structural model subjected to a static lateral loading). The most essential component of all existing nonlinear static procedures (NSPs) is the monotonic pushover analysis procedure. In fact, these two terms (i.e. the pushover analysis procedure and the NSP) are also sometimes used interchangeably in literature. It is the key to evaluate the quasi-static lateral inelastic response of structures. The basic principle of pushover analysis is to subject the floors of an inelastic structural model of building (after loaded with gravity loads) to an incrementally increasing lateral force pattern representing a simplified distribution of earthquake induced forces (Fig. 2). Subsequently, the 


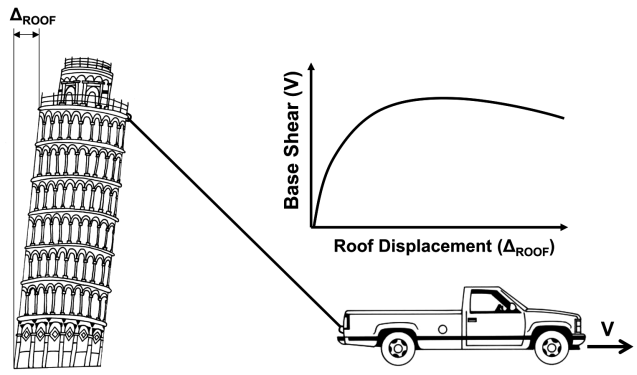

Fig. 2. The basic concept of the pushover analysis

strength and stiffness properties of every structural component are updated after each load increment to account for the reduced resistance of yielding components. This process is continued until the structure becomes unstable or until a predetermined target displacement is reached. The primary objective is to obtain the estimates of the global lateral strength, global displacement ductility and the failure mechanism of a structure under lateral forces induced by the earthquake ground motion. The pushover (or capacity) curves for the structure at a global level are generated by applying this procedure to the detailed structural models directly incorporating the anticipated nonlinearity of its components. These pushover curves are then idealized as simplified relationships and the expected maximum seismic deformation and other response quantities can then be determined using any established NSP. Compared to the linear static analysis procedures, the primary advantage of the NSPs is their ability to account for the redistribution of internal forces as the structural components experience nonlinearity under incremental lateral forces. This allows a clear understanding of variations in structural response and the achievement of various limit states as the structure enters in inelastic range.

Various NSPs are based on the idea that the detailed nonlinear structural models of buildings can be idealized as the equivalent single-degree-of-freedom (SDF) systems. The actual pushover curves of a full structure can be idealized to represent a nonlinear force-deformation relationship. This relationship is assigned to an equivalent SDF system which is then expected to represent the detailed nonlinear structural model. In other words, an equivalent SDF is "mapped" to the actual global behavior of the detailed structural model. This concept is illustrated in Fig. 3 where an approximated

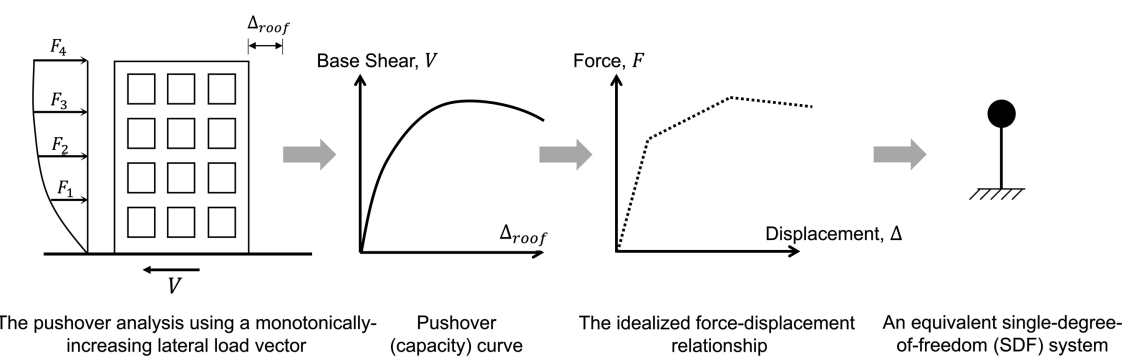

Fig. 3. The basic conversion of a detailed structural model in to an equivalent SDF system 
form of a capacity (pushover) curve is used as the governing force-displacement relationship of an equivalent SDF system.

\section{The NSPs Prescribed in Various Guidelines for the Seismic Performance Evaluation of Buildings}

The quest of simplifying the estimation of nonlinear seismic demands for practically convenient applications (using static analysis) have resulted in the development of two important approaches, i.e. the "equivalent linearization" and the "displacement modification". The procedures based on the equivalent linearization approach approximate the maximum displacement of a nonlinear SDF system by using its linear counterpart. Their underlying assumption is that a reasonable estimate of the seismic demands of a nonlinear SDF system can be conveniently obtained by replacing it with a modified linear elastic model. This assumption is the basis of all equivalent linearization methods and have remained a subject of immense research over last two decades. The properties of the "equivalent linear" SDF system are determined such that the difference in the dynamic responses of the equivalent linear SDF system and the actual nonlinear SDF system is minimum. Generally, this equivalent linear SDF system is defined by a relatively longer (or equivalent) natural period compared to the initial period of the actual nonlinear SDF system, and a higher (or equivalent) viscous damping compared to the initial inherent damping assigned to the actual nonlinear SDF system.

On the other hand, the procedures based on displacement modification approach approximate the maximum response of a nonlinear oscillator by multiplying the displacement of its elastic counterpart with a series of coefficients, each accounting for a specific aspect of inelastic action. In the equivalent linear procedures, the determination of likely maximum deformation of an existing structure (with a known lateral strength and an unknown ductility capacity) requires the process to be iterative. However, the displacement modification approach offers the convenience to be non-iterative and the modifying coefficients depend on easy-to-determine parameters including the natural time period, lateral yield strength factor (i.e. the lateral yield capacity normalized to the elastic strength capacity), site conditions and the characteristics of elastic pseudoacceleration response spectrum. This section will provide a brief overview of different NSPs as prescribed by various performance-based seismic evaluation guidelines.

\subsection{The Capacity Spectrum Method (CSM) in ATC 40}

The main NSP prescribed in the ATC 40 (1996) report entitled "Seismic Evaluation and Retrofit of Concrete Buildings", is based on the equivalent linearization approach (The Capacity Spectrum Method, CSM), which was originally developed as a rapid evaluation method for a pilot seismic risk project of the Puget Sound Naval Shipyard for the U.S. Navy in the early 1970s (Freeman et al. 1975). In this method, the capacity/pushover curve is converted to the "capacity spectrum" by means of point-by-point conversion to the modal spectral coordinates. This pushover curve is generated by subjecting the detailed nonlinear structural model to the first-mode inertia 
load vector. The base shear $\left(V_{b}\right)$ and roof displacement $\left(\Delta_{\text {roof }}\right)$ values on the capacity curves are converted to the corresponding spectral acceleration $\left(S_{a i}\right)$ and spectral displacement $\left(S_{d i}\right)$ values on the capacity spectrum using the Eqs. (1) and (2).

$$
S_{a}=\frac{V_{b}}{W / \alpha_{1}}
$$

and

$$
S_{d}=\frac{\Delta_{\text {roof }}}{P F_{1} \phi_{1, \text { roof }}}
$$

where $W$ is the seismic weight of the building (i.e. the sum of dead load and the likely live loads), $\alpha_{1}$ and $P F_{1}$ are the modal mass coefficient and the modal participation factor for the first vibration mode respectively, and $\phi_{1, \text { roof }}$ is the roof level amplitude of the first vibration mode shape. Every point on a capacity spectrum curve is associated with a unique spectral acceleration $\left(S_{a}\right)$, spectral velocity $\left(S_{v}\right)$, spectral displacement $\left(S_{d}\right)$ and natural period $(T)$. The seismic hazard is represented by a $5 \%$-damped acceleration response spectrum, which is reduced (using the expressions prescribed in the ATC 40 report) based on the effective damping ratio of an equivalent linear system. This reduced response spectrum is also converted to the Acceleration-Displacement Response Spectrum (ADRS) format using Eq. (3).

$$
S_{d}=\frac{T^{2}}{4 \pi^{2}} S_{a}(g)
$$

The modified response spectrum in the ADRS format is referred to as the "demand spectrum". This demand spectrum is overlaid with the capacity spectrum to find their intersection point which corresponds to a condition for which the seismic capacity is equal to the demand imposed on the structure. This point is called the "performance point" which is an estimate of the actual maximum displacement expected during an anticipated earthquake. The overall process is illustrated in Fig. 4.

Various studies have identified the inherent sources of uncertainties in the use of heavily damped (or reduced) demand spectra and the use of (effective) natural period

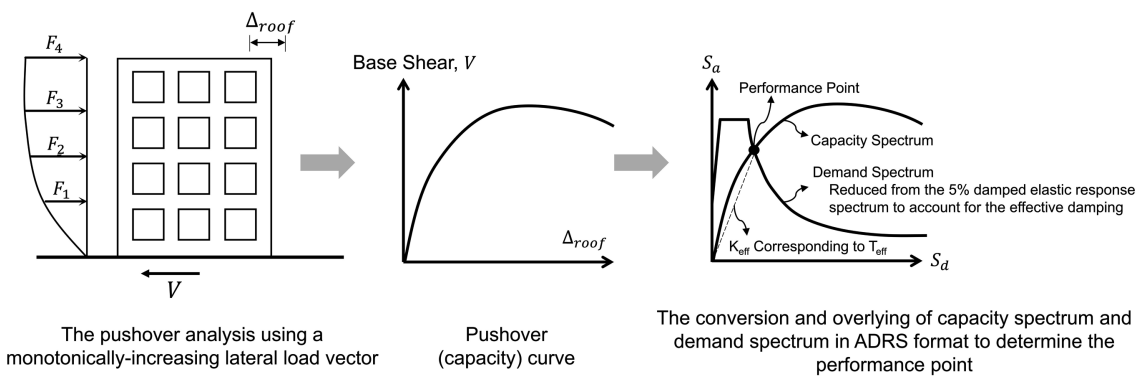

Fig. 4. The overall process of the capacity spectrum method (CSM) 
corresponding to intersection of the capacity and demand spectra. It was observed that the effective period at performance point may not be a true representative of the actual condition of structure and may have little to do with the realistic nonlinear dynamic response of the system (particularly for high levels of target displacement). Few studies (Miranda et al. 2002; Chopra et al. 2003) of the displacement demands as well as convergence issues for procedures mentioned in the ATC 40 report to determine the intersection point. As part of attempts to overcome such limitations, several other researchers suggested the use of inelastic response spectra (earlier proposed and applied in several applications by Bertero et al. (1991)) as the demand spectra, instead of reducing the elastic spectra by damping-dependent modification factors. This resulted in better estimations of peak inelastic displacement ratio compared to the ATC 40 iterative procedures to locate the performance point (Fajfar 2000; Miranda and Ruiz-Garcia 2002).

\subsection{The Displacement Coefficient Method (DCM) in FEMA 273 and FEMA 356}

An effective attempt to develop the more accurate NSPs was made by facilitating the idea that peak inelastic displacement can be directly estimated by multiplying the corresponding peak elastic displacement with the appropriate modifying factors. These factors represent the mean inelastic-to-elastic displacement ratios which may depend on the natural time period $(T)$, displacement ductility ratio $(\mu)$ and the lateral yield strength. Miranda (2001) compared the results obtained by using the inelastic demand spectra and the inelastic-to-elastic peak displacement ratios in the CSM, and concluded that later approach provides significantly better predictions of the target displacement.

This approach is prescribed as the displacement coefficient method (DCM) in the FEMA 273 (1997) and FEMA 356 (2000) reports. As mentioned above, it uses a series of appropriate factors or coefficients $\left(C_{0}, C_{1}, C_{2}\right.$, and $\left.C_{3}\right)$ to convert the maximum displacement of a linear SDF system to the maximum nonlinear displacement, which can then be used as the target displacement for the pushover analysis to get overall seismic demands. The modifying coefficients also depend on the characteristics of forcedeformation relationship of the idealized nonlinear SDF system (i.e. the representative SDF governed by an idealized pushover curve). Due to its convenient application, this approach was widely accepted and applied to various types of building structures. A brief overview of an improved version of this method will be presented next.

\subsection{Improvements in the Existing NSPs by FEMA 440}

The FEMA 440 (2005) report presented a comprehensive analysis program to develop the improved versions of both the capacity spectrum method (CSM) as well as the displacement coefficient method (DCM). This investigation consisted of determining the peak nonlinear displacements of a large number of SDF systems subjected to a large number of real ground motion records. For this purpose, the SDF systems with initial natural periods between 0.05 and $3 \mathrm{~s}$, and having nine different levels of lateral 
strengths were used. They are modeled with four different hysteretic behaviors (elastic perfectly plastic, stiffness-degrading, strength- and stiffness-degrading, and nonlinear elastic behavior). Based on the results obtained from this comprehensive parametric study, various improvements in both the CSM and DCM were proposed.

For the Capacity Spectrum Method (CSM), a more efficient bilinear approximation of the pushover curve is proposed. The expressions to estimate the effective time period and effective viscous damping (for reducing the elastic spectrum to an inelastic demand spectrum) were also improved. Similarly, the FEMA 440 report also provided the improved expressions for the displacement modifying coefficients for the DCM, which were later incorporated in the ASCE/SEI 41-06 (2007) and ASCE/SEI 41-13 (2013). The coefficient $C_{3}$ (from the FEMA 273 and FEMA 356 reports, accounting for the increased displacements due to the dynamic $P-\Delta$ effects) was suggested to be eliminated and replaced with a maximum limit on the normalized yield strength ratio $R_{\max }$ (which is intended to account for the dynamic instability). If the lateral yield strength of a system (normalized to its elastic strength demand) exceeds the $R_{\text {max }}$, a nonlinear dynamic procedure (NDP) should be used to capture the strength degradation and dynamic $P-\Delta$ effects to confirm the dynamic stability of the building. The next sub-section will discuss the DCM as prescribed in the ASCE/SEI 41-06 and ASCE/SEI 41-13 in its latest form.

\subsection{The NSP in ASCE/SEI 41-06 and ASCE/SEI 41-13}

The Nonlinear Static Procedure (NSP) defined in ASCE/SEI 41-06 (2007) utilizes the application of a single invariant load pattern (based on the first mode shape) to the structure, while the target displacement is determined using the improved version of the displacement coefficient method (DCM). An inelastic model directly incorporating the nonlinear load-deformation behaviors of the individual components of the building is subjected to a monotonically increasing lateral load pattern (representative of inertial forces developed during an earthquake), until a target displacement is achieved at the control node (usually the roof). This target displacement is intended to represent the maximum displacement likely to be experienced during the design earthquake and is calculated using the expression shown in Fig. 5.

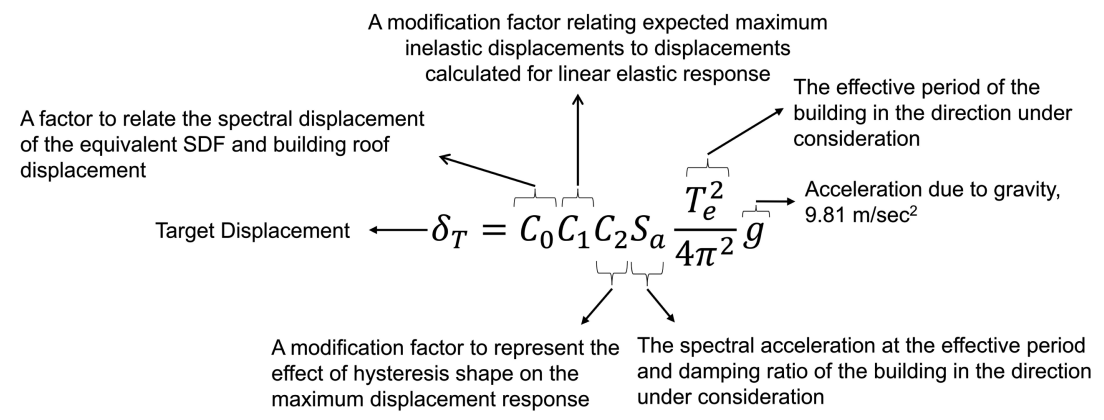

Fig. 5. The modification of the elastic spectral displacement to estimate the nonlinear peak roof displacement (target displacement) 
The ASCE/SEI 41-06 requires carrying out the analysis to at least $150 \%$ of the target displacement in order to encourage the engineers to investigate the likely building performance under the extreme loading conditions that exceed the design values. The nonlinear relationship between the base shear and lateral displacement of the control node is then replaced with an idealized force-deformation relationship to determine the effective lateral stiffness $\left(K_{e}\right)$ and effective yield strength $\left(V_{y}\right)$ of the building. These parameters are used to determine the effective time period $\left(T_{e}\right)$ and the normalized yield strength factor $(R)$. These two parameters (along with a site class factor $a$ ) are then used to finally determine the displacement modifying coefficients $C_{1}$ and $C_{2}$. The overall procedure is summarized in Fig. 6. For periods less than $0.2 \mathrm{~s}$, the coefficient $C_{1}$ is taken as the value at $T=0.2 \mathrm{~s}$, while for periods greater than $1 \mathrm{~s}$, the equal-displacement approximation is assumed to hold good and $C_{1}$ is taken as 1 , indicating that the peak nonlinear displacement tends to remain equal to the peak linear displacement. Similarly, for periods greater than $0.7 \mathrm{~s}$, there is no significant hysteretic effect and the coefficient $C_{2}$ is taken as 1 . For buildings with negative post-yield stiffness, the maximum strength ratio $R_{\max }$ is required to be determined in accordance with Eq. (4).
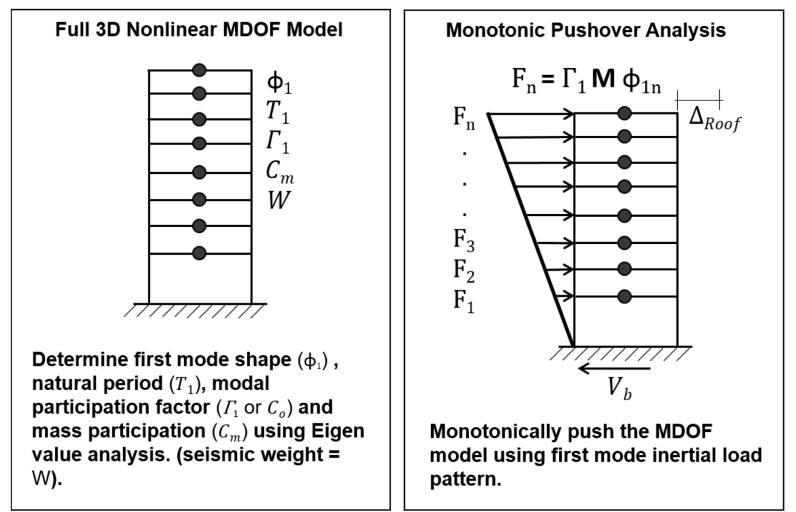

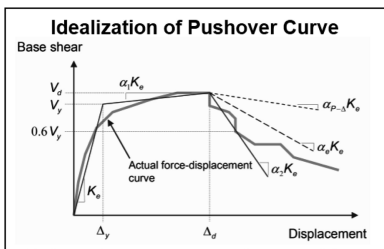

Get pushover curve and convert to an idealized force-deformation relationship. Extract $K_{e}$ and $V_{y}$ (ASCE 41-13).

Using initial time period $\left(T_{1}\right)$, pick spectral acceleration $\left(S_{a}\right)$ value from elastic response spectrum and determine $\mathbf{R}$ using

$$
R=\frac{S_{a}}{V_{y} / W} C_{m}
$$

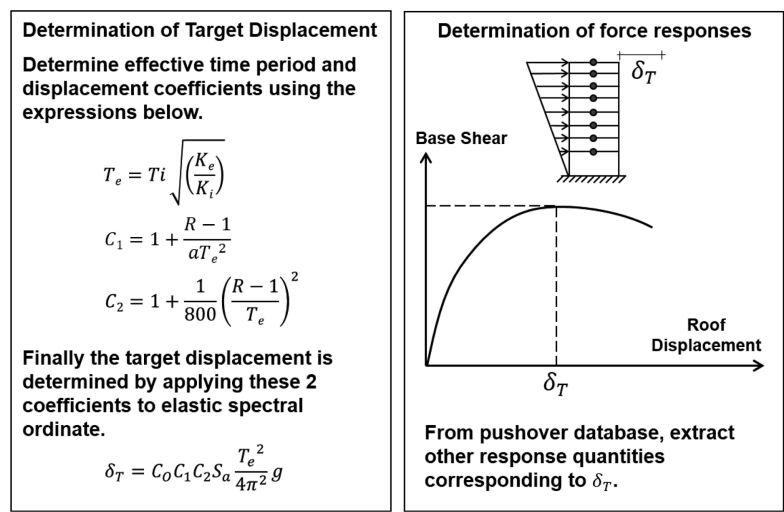

Fig. 6. An overview of the ASCE 41-13 NSP (the displacement coefficient method) 


$$
R_{\max }=\frac{\Delta_{d}}{\Delta_{y}}+\frac{\left|\alpha_{e}\right|^{-h}}{4}
$$

where $\Delta_{d}$ is lesser of the target displacement $\left(\delta_{T}\right)$ or the displacement at maximum base shear. While $\Delta_{y}$ is the displacement at effective yield strength. $h=1+0.15 \ln (T)$; and $\alpha_{e}$ is the effective negative post-yield slope ratio (i.e. the ratio of the negative post-yield slope to the slope of initial line in bilinear approximation). Figure 7 graphically shows the ASCE/SEI 41-13 (2013) expressions for the displacement modifying coefficients $C_{1}$ and $C_{2}$ for different values of the normalized yield strength factor $(R)$ and the site class factor $(a)$.
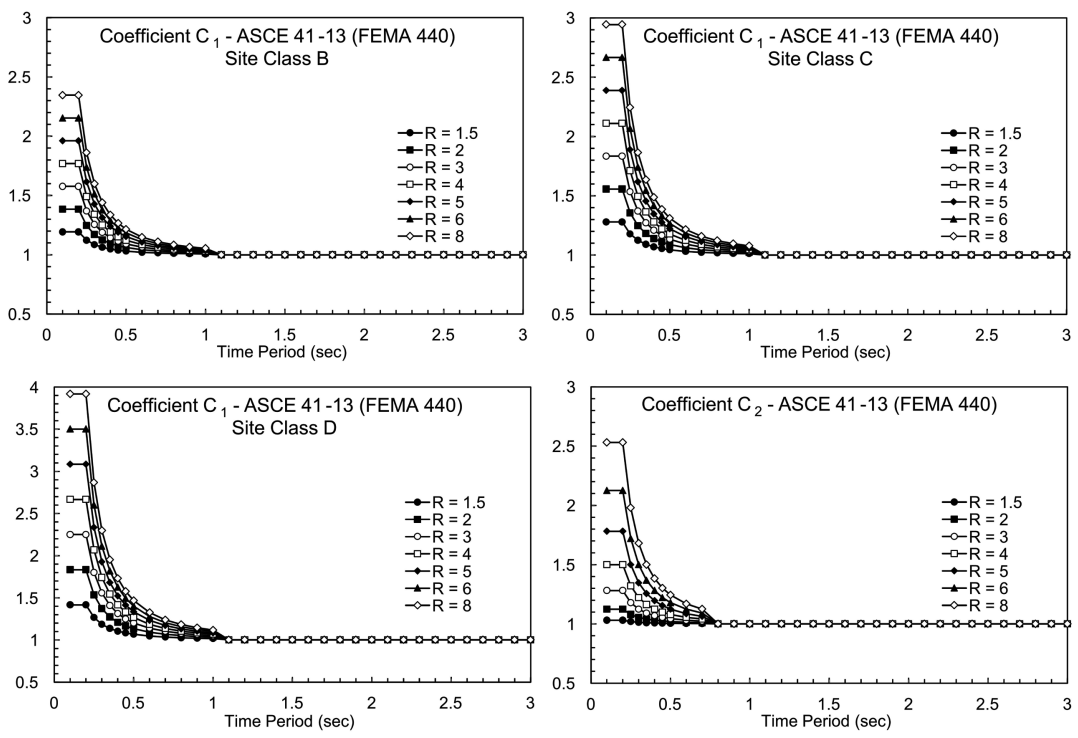

Fig. 7. The ASCE/SEI 41-13 relationships for displacement modifying coefficients $C_{1}$ and $C_{2}$

\section{The Multi-Mode Pushover Analysis Procedures}

In this section, a summary of various studies is presented which are focused on the enhancements and variations in currently available pushover analysis methods in last two decades. Most of the improvements were proposed to reduce the inherent assumptions as well as for the convenient applicability to any particular structural system. Historically, the conventional pushover analyses are based on the use of invariant lateral load vector. However, in recent years, relatively complex methods have also been proposed which include for example, the use of lateral load vectors that progressively change patterns during the analysis to account for the effect of higher vibration modes or for the changes in the deflected shape of building. Most of such ambitious approaches are not practically convenient to implement for the common practicing structural engineers, and therefore, their general applicability is still a subject of research. 


\subsection{A Review of Developments in Last Two Decades}

The high-rise buildings may have a significant response contribution from the higher modes as well (beside the first vibration mode), especially in force demands. Various methods have been proposed to account for the multiple-degrees-of-freedom (MDF) effects in the pushover analysis. These multi-mode methods use a simplified representation of the MDF system as a combination of various elastic or inelastic SDF systems, each mimicking the behavior of a particular vibration mode of the MDF system. One of the earlier attempts to account for the effects of higher vibration modes in the pushover analysis was made by Sasaki et al. (1998). In this study, a Multi-Mode Pushover (MMP) analysis procedure is proposed to evaluate the effects of higher vibration modes and to identify the failure mechanisms due to these effects. This method was based on the use of capacity spectrum method (CSM) for each significant vibration mode of an MDF system. In 2002, Chopra and Goel (2002) proposed the Modal Pushover Analysis (MPA) procedure (as an extension of single-mode pushover analysis) for estimating the seismic demands of buildings. The response contributions from higher vibration modes can be considered in this procedure by applying a series of independent pushover analyses, each using the modal inertia load pattern for a particular vibration mode. Later, a simplified version referred to as the Modified Modal Pushover Analysis (MMPA) (Chopra and Goel 2004) was proposed in which the response contributions from higher vibration modes are assumed to remain elastic. Jan et al. (2004) proposed another simplified pushover analysis procedure considering higher-mode effects. A new expression to determine the lateral load pattern (combining the effects of first and second vibration modes) and an improved modal combination rule was proposed. Kalkan and Kunnath (2004) proposed the Method of Modal Combinations (MMC) based on the invariant force distributions determined by factored combination of independent modal load contributions.

An important category of the pushover analysis methods is the one using the adaptive lateral force vectors. Gupta and Kunnath (2000) developed a modal scaling technique which is applied in an adaptive manner. In this procedure, the incremental response quantities are calculated and combined using a modal combination rule. Antoniou et al. (2002) also proposed an adaptive modal pushover method in which the seismic loads are directly combined to define the instantaneous load patterns at each analysis step. Vamsatsikos and Cornell (2002) presented an incremental dynamic analysis (IDA) procedure for developing the intensity-demand curves (similar to the pushover curves). This procedure in intended to account for all the dynamic variations in response under a specific ground motion. However, this procedure is relatively tedious as the repeated NLRHA procedure is required to perform for a large number of scaled ground motion records. Attard and Fafitis (2005) introduced the optimal multi-mode pushover analysis which uses a variant inertial load pattern determined by updating the structure's vibration properties at each stage of yielding. For each step, a single optimal vibration mode shape is determined and an equivalent SDF system is defined. The lateral force distribution determined using the modal properties of previous step is applied until the yielding occurs. The degraded stiffness and vibration properties are determined to update the characteristics of representative SDF system, and the process continues to next analysis step. Kalkan and Kunnath (2006) further 
proposed a pushover analysis procedure based on the Adaptive Modal Combinations (AMC) attempting to integrate the concepts of classical capacity spectrum method, the adaptive method proposed by Gupta and Kunnath (2000), and the modal pushover analysis. In this method, the target displacement is estimated and updated during the same analysis using the energy-based modal capacity curves and constant-ductility capacity spectra, thus avoiding the requirement to estimate the target displacement prior to the analysis. Aschheim et al. (2007) proposed a procedure requiring the repeated application of ground motion records to nonlinear structure to match the target demand obtained from the NSP. However, this procedure, similar to the IDA procedure, is also tedious and offers little simplification over the detailed NLRHA procedure of a nonlinear structural model.

Poursha et al. (2009) proposed an analysis procedure referred to as the Consecutive Modal Pushover (CMP) in which the overall response quantities are estimated by enveloping the results of multi-stage and single-stage pushover analyses. It recommends a consecutive application of invariant load vectors corresponding to the first three vibration modes (in stages) in a single pushover analysis. The first mode forces are applied until a predetermined roof displacement is reached. The analysis continues with the incremental forces corresponding to the second vibration mode pattern which, after a certain displacement, changes to the third mode pattern. The study concluded that the roof drift and plastic hinge rotation estimates predicted by the CMP analysis procedure are generally better compared to those obtained using the MPA procedure. More recently, Sucuoglu and Gunay (2011) proposed a Generalized Pushover Analysis (GPA) procedure based on conducting the pushover analyses using different generalized force vectors. These force vectors are determined by combining the modal forces and is intended to represent the effective lateral force distribution at maximum inter-story drift of the selected story. The envelope results are obtained after a series of analyses under these generalized forces. Figure 8 summarizes the wide range of various pushover analysis procedure available in the literature.

The adaptive pushover analysis procedures featuring the ability to adjust the pushover load vectors during the analysis (to account for the effect of higher vibration modes or the stiffness degradation on the story force distribution) could not grab much attention from the practicing engineers because of inherent complexities involved in the computer implementations of such procedures. They require the solution of eigenvalue analysis at each load increment. This results in an increase in both the analysis time and computational cost. On the other hand, the multi-mode pushover analysis procedures using the invariant inertial force distributions for each mode are comparatively easier to perform, due to their convenient implementation in various commercial software packages for nonlinear structural analysis. Various software have completely automated the process by enabling the users to directly select the pushover load distribution based on any calculated mode shape and the story masses.

\subsection{The Modal Pushover Analysis (MPA) Procedure}

The modal pushover analysis (MPA) procedure, originally proposed by Chopra and Goel (2002), is the most well-known multi-mode pushover analysis procedure. It is 


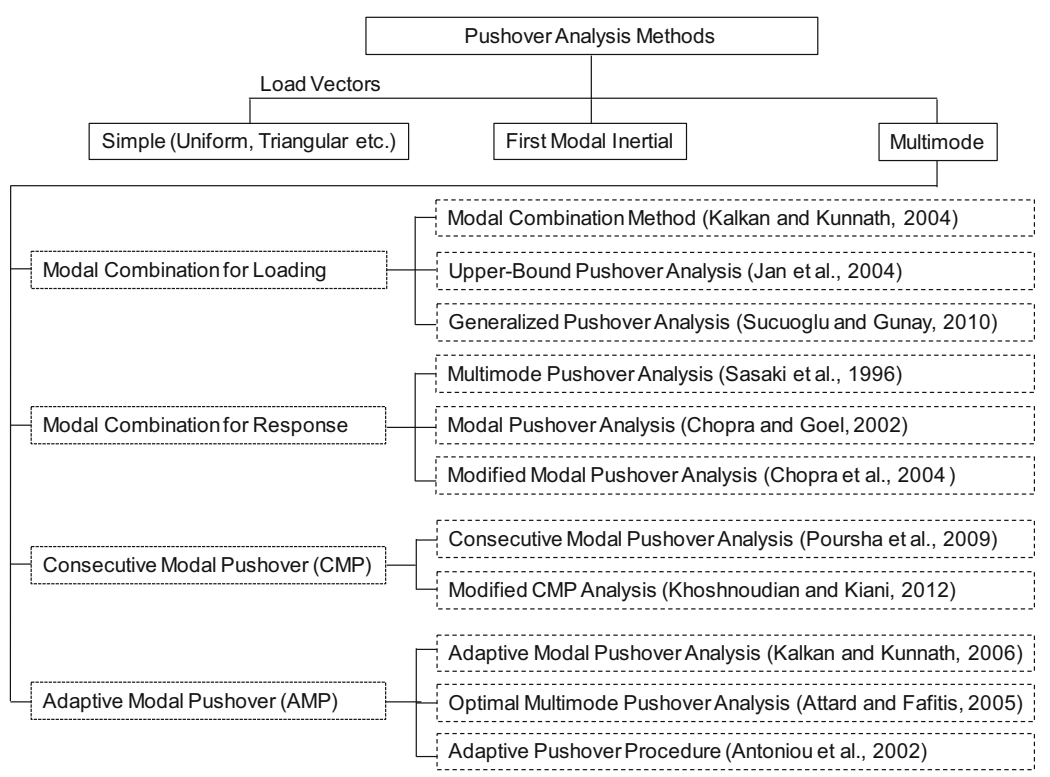

Fig. 8. A range of available pushover analysis procedures

based on the assumptions that the response of nonlinear MDF systems can be approximately described as a superposition of responses from few significant vibration modes, which are assumed to remain independent of each other. Although, both of these assumptions i.e. (a) superposition of modal responses, and (b) the modal coupling is negligible, are strictly valid only for the linear elastic systems, Chopra and Goel (2002) have demonstrated that a reasonably accurate estimates of nonlinear seismic demands can still be obtained using this procedure. As mentioned earlier, this procedure recommends a series of pushover analyses, each using the lateral load vector with distribution proportional to a particular vibration mode shape and story masses. The pushover analysis is carried out for each significant vibration mode until a target value of roof displacement (for that particular mode) is achieved. This target displacement for each mode can be determined by constructing a representative nonlinear SDF system for that vibration mode and subjecting it to the ground motion records. These representative nonlinear SDF systems for each mode are modeled by the idealized forms of the corresponding pushover curves. Once the peak inelastic displacements for each mode are determined, they can be converted to corresponding target roof drifts and hence, all important seismic demands (e.g. inter-story drift ratios, story shears and overturning moments etc.) can be extracted from the pushover database at those target roof drifts, for each mode. The individual modal response quantities are then combined using an appropriate modal combination rule (usually SRSS, if the natural time periods are well-separated).

For the linear elastic systems, the MPA procedure becomes same as elastic response spectrum analysis (RSA) procedure. It is expected to provide better results compared to the code-based NSPs due to inclusion of higher-mode effects. Various further 
simplifications in terms of convenient estimation of target displacements for each mode, are also proposed and applied in literature. Owing to its conceptual simplicity and convenient applicability, the evaluation of this procedure for different types of structural systems, has remained a subject of considerable research in last decade. Figure 9 presents a schematic overview of the modal pushover analysis (MPA) procedure.

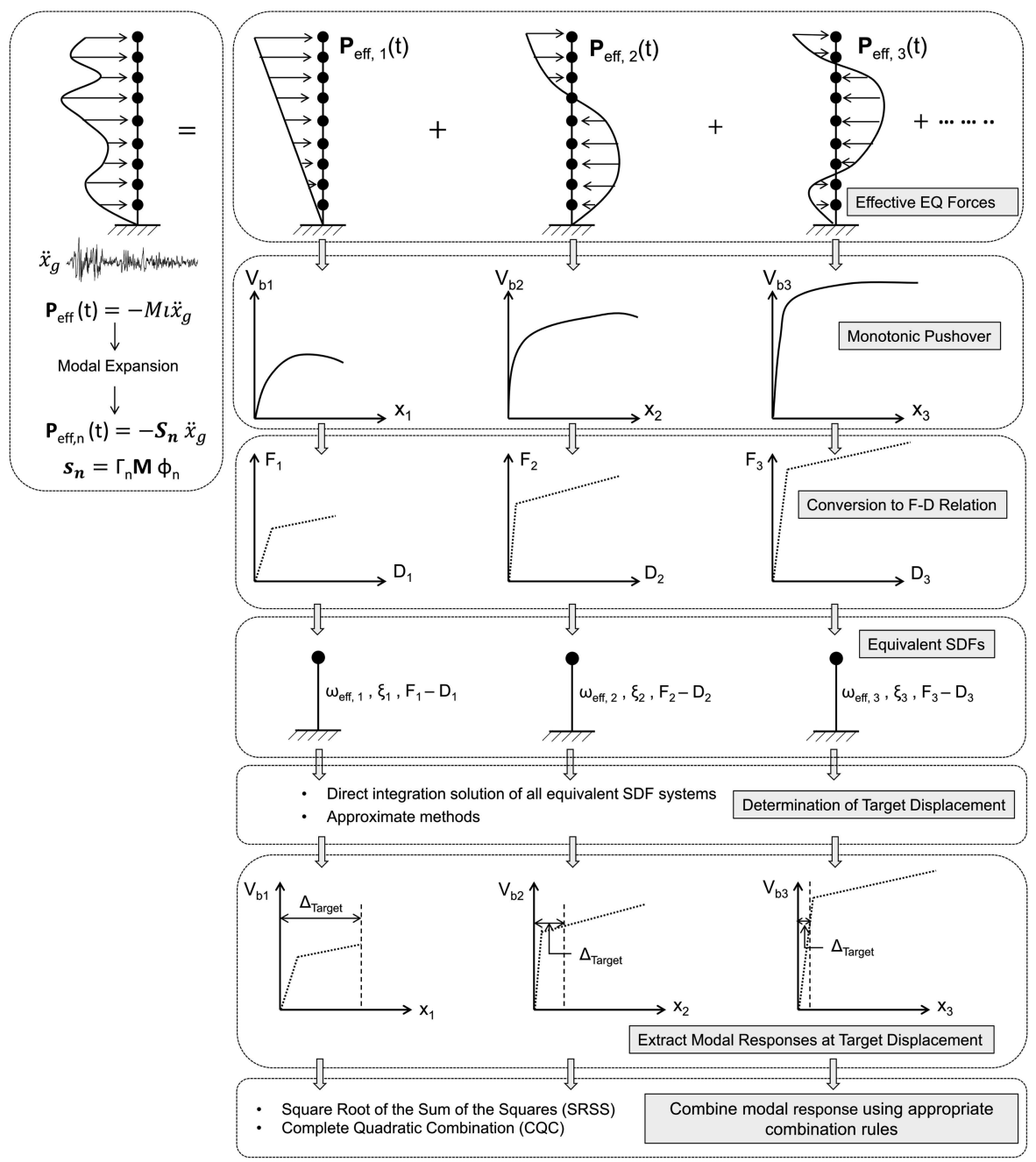

Fig. 9. An overview of the modal pushover analysis (MPA) procedure (Chopra and Goel 2002) 


\section{How Accurate are the NSPs? - Challenges and Issues}

Several studies have identified the challenges associated with the applicability and practicality of NSPs with reference to their accuracy in predicting the nonlinear response. The detailed nonlinear response history analysis (NLRHA) procedure is always considered a benchmark for the comparison to evaluate how well a simplified procedure can capture various complex aspects of nonlinearity. In some studies, the experimental results are also used as benchmark. Compared to the linear analysis procedures, the NSPs are considered to be less conservative and more accurate. They also provide a valuable insight of various phenomenon (e.g. yield mechanism), which are not possible to understand using the linear static procedures. Depending upon the demand parameter of interest, some analysis options can provide better estimates than others. For example, for the determination of target displacement, the NLRHA procedure applied to a SDF system (representing either a complete structure or its any particular vibration mode) using a relatively large number of ground motions will provide a better insight in to the uncertainty due to record-to-record variability. However, if a reasonably accurate and quicker estimate of only the peak global displacement is required, the displacement modification approach can serve the purpose better and with great ease. The NIST GCR 10-917-9 (2010) report has identified some of the challenges faced by the NSPs related to the nonlinear modeling. Even with well-prepared models sophisticated enough to capture all important failure modes, the NSPs were observed to miss various important behaviors. Various studies comparing the results obtained from the NSPs with those obtained from the detailed NLRHA procedure attribute the difference to a number of reasons, limitations and associated challenges, some of which are mentioned as follows.

(a) Although all the available NSPs vary in different features including the choice of lateral load vectors, modeling of equivalent SDF systems, and the determination of target displacement, one common aspect is the determination of quasi-static response of structure using the pushover analysis. It is well established that the quasi-static response is limited in its ability to capture the complex dynamic behavior of multiple-degree-of-freedom (MDF) structures (using a step-by-step series of static analyses) and it cannot be considered as a substitute for the full nonlinear dynamic response. Most code-based NSPs only consider the pushover analysis for first vibration mode. Those considering higher modes are computationally more demanding and in some cases (e.g. for significantly yielding systems and for structures with heavily coupled vibration modes), may not be regarded as the convenient alternative of the detailed NLRHA procedure. The NSPs are also incapable of capturing various inelastic failure mechanisms with no information about the dynamic characteristics of any response quantity (e.g. the complete time history, number of cycles for fatigue analysis or the time step corresponding to the maximum response). Moreover, the pushover procedures are also unable to explicitly account for the dynamic $P-\Delta$ effects and dynamic instability. Recently, the ASCE 41-13 (2013) has imposed a maximum limit on the lateral yield strength (normalized to elastic demand) to implicitly account for 
the dynamic instability. Weak structures, not fulfilling this criterion, are not eligible for the application of NSP.

(b) In single-mode pushover analysis procedures, the arbitrary choice of the invariant load patterns to represent the distribution of equivalent static seismic loads, has also received some criticism in the literature. Various studies have evaluated the effects of different lateral load patterns including the modal inertia pattern, constant or rectangular pattern, inverted triangular pattern or other patterns prescribed in different seismic evaluation guidelines. Ideally, the incrementally-increasing pushover load pattern should be compatible with the resulting pattern of nonlinear deformation. Considering this compatibility, various studies have shown that the adaptive patterns can result in a better demand estimates compared to the invariant patterns.

(c) A complete structural response is always characterized by the actual hysteretic behavior incorporating all important phenomenon including strength and stiffness degradation, the effect of pinching (if any), residual deformations and the energy dissipation. For the modeling and solution of equivalent nonlinear SDF systems to get the target displacement, the NSPs are also lacking behind in this important aspect. Although the ASCE 41-13 have considered four important hysteretic models to derive the displacement modifying coefficients (FEMA 440), an explicit consideration of the close-to-real cyclic behavior of a building is expected to be more accurate compared to the approximations based on few generalized hysteretic behaviors. An important improvement in the multi-mode pushover analyses may be the use of close-to-real hysteretic models (obtained by idealizing the reversed-cyclic pushover curve) for modeling the equivalent SDF systems.

(d) The multi-mode pushover analysis procedures although are considered relatively more accurate compared to the conventional single-mode procedures, they are also limited in their ability to capture the dynamic response variations due to the continuously changing modal interactions during the random seismic loading. Most of the multi-mode procedures are based on assumption that modal coupling is weak and the response of various vibration modes can be considered independent of each other. These procedures generally recommend to use the SRSS modal combination rule to combine the peak modal responses which was originally used for the linear elastic systems. The adequacy of SRSS combination rule for the nonlinear and yielding systems is questionable. This problem of modal combination can be avoided by an approximate nonlinear dynamic procedure, referred to as Uncoupled Modal Response History Analysis (2007) procedure. As the name indicates, it still ignores the modal coupling in nonlinear range, however the overall response history is computed by directly summing (in time domain) the individual nonlinear modal response histories obtained by the direct integration solution of all the equivalent modal nonlinear SDF systems.

(e) As mentioned earlier, the displacement coefficient method (DCM) recommends that for structures with the fundamental period greater than $1 \mathrm{~s}$, there is minimal effect of nonlinearity on the peak displacement which can be assumed equal to the corresponding elastic displacement $\left(C_{1}=1\right)$. Similarly, for structures with the fundamental period greater than $0.7 \mathrm{~s}$, the effect of hysteresis loops is also negligible enough to ignore for practical purposes $\left(C_{2}=1\right)$. Both of these 
recommendations are based on the FEMA 440 investigation. The FEMA 440 report defines two different spectral ranges pertaining to the adequacy of this well-known "equal-displacement assumption" (i.e. the first short-period range where this assumption is valid, and the second where the inelastic peak displacement is significantly higher compared to the peak elastic displacement). However, the separating period (for both spectral ranges) of $1 \mathrm{~s}$ for $C_{1}$ and $0.7 \mathrm{~s}$ for $C_{2}$ may not represent a wide range of structural systems with different hysteretic responses. Moreover, various studies have also indicated the significant uncertainties in the values of displacement modifying coefficients in the short-period range, since the actual inelastic-to-elastic peak displacement ratios were found to be fluctuating rapidly at periods less than $1 \mathrm{~s}$.

(f) Most of the NSPs prescribed in seismic design guidelines and codes are not applicable to the high-rise buildings (usually defined as the buildings with fundamental natural period greater than $1 \mathrm{~s}$, or the buildings with significant response contributions from the higher vibration modes). For a variety of proposed multi-mode pushover analysis procedures in literature, usually there are no direct recommendations available on the building types and/or structural systems for which these procedures can be considered the most accurate.

(g) An important area of the performance-based seismic evaluation of new and existing buildings is the consideration of phenomena pertaining to soil-structure interaction (SSI). The available NSPs are unable to explicitly account for such interaction. Recently, with reference to the displacement coefficient method (DCM), Khoshnoudian et al. (2013) computed the inelastic-to-elastic peak displacement ratios for SDF systems modeled with the support conditions representing soil behavior (instead of the fixed support). This study concluded that the equal-displacement assumption is not valid for the structures with significant soil-structure interaction and the effects of soil flexibility are more significant for weaker structures compared to stiff ones. In another recent study, Ghannad and Jafarieh (2014) examined the simultaneous effects of soil-structure interaction, foundation uplift and the inelastic behavior of superstructure on the total displacement response. This study also proposed a new factor " $C_{d 3}$ " to account for the SSI effects while determining the target displacement for uplifting soilstructure systems.

(h) Another limitation associated with the applicability of the NSPs to a wide spectrum of structures is their inability to capture the bi-directional and torsional responses. Relatively less research work has been done related to the improvement of NSPs for their application to complex-natured, innovative and architecturally-advanced structural systems (e.g. multiple towers on a single podium). Chopra et al. (2004) version of the MPA procedure for unsymmetric-plan buildings in which, unlike an inertial force distribution with a single force at each story level, two lateral forces and a torque is applied at each floor for all considered vibration modes. The modal demands contributions are then combined by the complete quadratic combination (CQC) rule to obtain an overall estimate of the inelastic seismic demands. The accuracy of all such attempts to account for the torsional response in the NSPs is still a subject of research and discussion. 


\section{Concluding Remarks}

A review of developments, issues and challenges related to various nonlinear static procedures (NSPs) for the performance-based seismic evaluation of existing and new buildings, is presented. Although with the advent of latest computing tools and software packages, the detailed nonlinear response history analysis (NLRHA) procedure is becoming relatively easy to perform, the NSPs still retain a reasonable degree of interest among the practicing engineers owing to their simplicity and convenient practical use. This summary of various approaches and the code-based NSPs shows that there is no one single method which can be considered consistently accurate as well as equally applicable to all the structural systems. In last two decades, various studies have identified the limitations and associated challenges in the existing NSPs and proposed different improvements based on rigorous evaluations of various nonlinear phenomena. Although the NSPs may not claim the accuracy and wider applications comparable to the detailed NLRHA procedure, they are still considered a valuable tool to gain insight in the complex nonlinear behavior and response of building structures.

Acknowledgements. Author is thankful to Prof. Dr. Pennung Warnitchai for his valuable supervision and continuous support during this study. Thanks are also due to AIT Solutions (AITS Thailand), Asian Institute of Technology (AIT Thailand), Higher Education Commission (HEC Pakistan) and National University of Sciences and Technology (NUST Pakistan) for providing research facilities and funding.

\section{References}

Antoniou, S., Rovithakis, A., Pinho, R.: Development and verification of a fully adaptive pushover procedure. In: Proceedings of the 12th European Conference on Earthquake Engineering, London, Paper no. 882 (2002)

Aschheim, M., Tjhinb, T., Comartin, C., Hamburger, R., Inel, M.: The scaled nonlinear dynamic procedure. Eng. Struct. 29(7), 1422-1441 (2007)

ASCE/SEI 41: Seismic Rehabilitation of Existing Buildings (ASCE/SEI 41-06). American Society of Civil Engineers, Reston (2007)

ASCE/SEI 41: Seismic Rehabilitation of Existing Buildings (ASCE/SEI 41-13). American Society of Civil Engineers, Reston (2013)

ATC 40: Seismic evaluation and retrofit of concrete buildings, Redwood City, California (1996)

Attard, T., Fafitis, A.: Modeling of higher-mode effects using an optimal multi-modal pushover analysis. WIT Trans. Built Environ. 81, 405-414 (2005)

Bertero, V.V., Anderson, J.C., Krawinkler, H., Miranda, E.: Design guidelines for ductility and drift limits. Earthquake Engineering Research Center Report (91/15) (1991)

Chopra, A.K., Goel, R.K.: A modal pushover analysis procedure for estimating seismic demands for buildings. Earthq. Eng. Struct. Dyn. 31(3), 561-582 (2002)

Chopra, A.K., Goel, R.K., Chintanapakdee, C.: Statistics of single-degree-of-freedom estimate of displacement for pushover analysis of buildings. J. Struct. Eng. 129(4), 459-469 (2003)

Chopra, A.K., Goel, R.K.: A modal pushover analysis procedure to estimate seismic demands for unsymmetric-plan buildings. Earthq. Eng. Struct. Dyn. 33(8), 903-927 (2004)

Chopra, A.K., Goel, R.K., Chintanapakdee, C.: Evaluation of a modified MPA procedure assuming higher modes as elastic to estimate seismic demands. Earthq. Spectra 20(3), 757778 (2004) 
Chopra, A.K.: Dynamics of Structures: Theory and Applications to Earthquake Engineering. Pearson/Prentice Hall, Upper Saddle River (2007)

Fajfar, P.: A nonlinear analysis method for performance-based seismic design. Earthq. Spectra 16 (3), 573-592 (2000)

FEMA 273: NEHRP guidelines for the seismic rehabilitation of buildings, vol. 1. Federal Emergency Management Agency (1997)

FEMA 356: Prestandard and Commentary for the Seismic Rehabilitation of Buildings. FEMA-356, Federal Emergency Management Agency Washington (2000)

FEMA 440: Improvement of nonlinear static seismic analysis procedures. Applied Technology Council, Washington DC (2005)

Freeman, S.A., Nicoletti, J.P., Tyrell, J.V.: Evaluations of existing buildings for seismic risk - a case study of puget sound naval shipyard, Bremerton, Washington. In: Proceedings of the 1st US National Conference on Earthquake Engineering, pp. 113-122. EERI, Oakland (1975)

Ghannad, M.A., Jafarieh, A.H.: Inelastic displacement ratios for soil-structure systems allowed to uplift. Earthq. Eng. Struct. Dyn. 43(9), 1401-1421 (2014). doi:10.1002/eqe.2405

Gupta, B., Kunnath, S.K.: Adaptive spectra-based pushover procedure for seismic evaluation of structures. Earthq. Spectra 16(2), 367-392 (2000)

Jan, T.S., Liu, M.W., Kao, Y.C.: An upper-bound pushover analysis procedure for estimating the seismic demands of high-rise buildings. Eng. Struct. 26(1), 117-128 (2004)

Kalkan, E., Kunnath, S.K.: Method of modal combinations for pushover analysis of buildings. In: Proceedings of the 13th World Conference on Earthquake Engineering (2004)

Kalkan, E., Kunnath, S.K.: Adaptive modal combination procedure for nonlinear static analysis of building structures. J. Struct. Eng. 132(11), 1721-1731 (2006)

Khoshnoudian, F., Kiani, M.: Modified consecutive modal pushover procedure for seismic investigation of one-way asymmetric-plan tall buildings. Earthq. Eng. Eng. Vib. 11, 221 (2012). doi:10.1007/s11803-012-0112-6

Khoshnoudian, F., Ahmadi, E., Nik, F.A.: Inelastic displacement ratios for soil-structure systems. Eng. Struct. 57, 453-464 (2013)

Miranda, E.: Approximate seismic lateral deformation demands in multistory buildings. J. Struct. Eng. 125(4), 417-425 (1999)

Miranda, E., Akkar, S.: Evaluation of approximate methods to estimate target displacements in nonlinear static procedures. In: Report. PEER-2002/21, Proceedings of the 4th US-Japan Workshop on Performance-Based Earthquake Engineering Methodology for Reinforced Concrete Building Structures, pp. 75-86 (2002)

Miranda, E., Ruiz-García, J.: Evaluation of approximate methods to estimate maximum inelastic displacement demands. Earthq. Eng. Struct. Dyn. 31(3), 539-560 (2002)

Miranda, E.: Estimation of inelastic deformation demands of SDOF systems. J. Struct. Eng. 127 (9), 1005-1012 (2001)

NEHRP NIST GCR 10-917-9: Applicability of nonlinear multiple-degree-of-freedom modeling for design. National Institute of Standards and Technology (2010)

Poursha, M., Khoshnoudian, F., Moghadam, A.S.: A consecutive modal pushover procedure for estimating the seismic demands of tall buildings. Eng. Struct. 31(2), 591-599 (2009)

Sasaki, K.K., Freeman, S.A., Paret, T.F.: Multi-mode pushover procedure (MMP) - a method to identify the effects of higher modes in a pushover analysis. In: Proceedings of the 6th US National Conference on Earthquake Engineering (1998)

Sucuoglu, H., Gunay, M.S.: Generalized force vectors for multi-mode pushover analysis. Earthq. Eng. Struct. Dyn. 40, 55-74 (2011)

Vamvatsikos, D., Cornell, C.A.: Incremental dynamic analysis. Earthq. Eng. Struct. Dyn. 31(3), 491-514 (2002) 